Article

\title{
Rapid Paper-Based System for Human Serum Creatinine Detection
}

\author{
Lung-Ming Fu ${ }^{1,2,3,+}$, Chin-Chung Tseng ${ }^{4,+}$, Wei-Jhong Ju ${ }^{1}$ and Ruey-Jen Yang ${ }^{3, *}$ \\ 1 Graduate Institute of Materials Engineering, National Pingtung University of Science and Technology, \\ Pingtung 912, Taiwan; loudyfu@mail.npust.edu.tw (L.-M.F.); david6767@gmail.com (W.-J.J.) \\ 2 Department of Biomechatronics Engineering, National Pingtung University of Science and Technology, \\ Pingtung 912, Taiwan \\ 3 Department of Engineering Science, National Cheng Kung University, Tainan 701, Taiwan \\ 4 Department of Internal Medicine, College of Medicine, National Cheng Kung University and Hospital, \\ Tainan 704, Taiwan; chinchun@mail.ncku.edu.tw \\ * Correspondence: rjyang@mail.ncku.edu.tw; Tel.: +886-627-575 (ext. 63343) \\ + These authors contributed equally to this work.
}

Received: 9 April 2018; Accepted: 21 May 2018; Published: 28 May 2018

\begin{abstract}
An integrated system consisting of a paper-based chip and a smart detection device is proposed for determining the human serum creatinine concentration based on Jaffé reaction theory. In the proposed approach, the reaction zone of the paper-based chip is implanted with picric acid and $\mathrm{NaOH}$ reagent and dried at $35^{\circ} \mathrm{C}$ for $20 \mathrm{~min}$. Human serum creatinine is dripped onto the reaction zone of the chip. A Jaffé reaction is induced by heating the chip at $37^{\circ} \mathrm{C}$ for $5 \mathrm{~min}$ and the creatinine concentration is then derived by analyzing the RGB (red, green and blue) intensity of the resulting Janovsky complex using self-written analysis software installed on a smartphone. The validity of the proposed method is demonstrated using control samples with creatinine concentrations ranging from $0.2 \sim 8 \mathrm{mg} / \mathrm{dL}$. The detection results obtained for 32 real-world creatinine samples are shown to be in excellent agreement with those obtained using a standard macroscale method $\left(R^{2}=0.9994\right)$. Overall, the results show that the proposed system provides a compact, low-cost and reliable approach for human serum creatinine concentration detection.
\end{abstract}

Keywords: paper-based chip; smart detection device; creatinine; Jaffé reaction

\section{Introduction}

Creatinine is an end-product of creatine metabolism and is one of the most useful analytes for the assessment of renal function. In normal healthy individuals, the typical reference ranges for serum creatinine are 0.5 to $1.0 \mathrm{mg} / \mathrm{dL}$ for women and 0.7 to $1.2 \mathrm{mg} / \mathrm{dL}$ for men [1,2]. In healthy humans, creatinine is continuously excreted by the kidneys at a rate of around $1.6 \sim 1.7 \%$ per day [3]. Thus, increasing levels of creatinine in serum (or decreasing levels in urine) provide a possible indication of kidney failure. The creatinine concentration is also employed as a correction factor for fluctuations in the urine volume and is thus useful in accurately determining the micro-albumin/creatinine ratio. Consequently, sensitive and accurate assays for measuring the creatinine level in blood and urine samples are of significant interest in the clinical diagnostics field.

Numerous approaches for creatinine detection have been reported in the literature, including Jaffé kinetic assays [4-6], enzyme reactions [7], capillary electrophoresis [8], chemiluminescence [9], chromatography [10], molecular imprinted polymer (MIP) assays [11], spectrophotometry [12,13], liquid chromatography-tandem mass spectrometry (LC-MS/MS) [14], potentiometric sensors [15,16], electrochemical sensors [17,18], colorimetry [19,20], pH sensors [21,22], amperometric sensors [23,24] 
and nanoparticle-enhanced sensors [25-27]. Although the results of these common methods provide accurate and reliable results, while almost all these instruments are bulky, expansive and require complicated operations.

Recent years have seen a growing interest in micro-total analysis systems ( $\mu$ TAS) and lab-on-a-chip (LoC) devices. Microfluidic systems and microfluidic paper-based devices ( $\mu$ PADs) offer many advantages over traditional devices, including a reduced reagent consumption, a faster analysis time, a lower cost, an improved portability and better disposability. As a result, they are regarded as extremely promising candidates for point of care testing (POCT) and disease screening applications in the developing world [28-32]. Various microfluidic systems for the monitoring and diagnosis of disorders such as cardiovascular disease, diabetes, cancer and renal disease have been proposed in the literature [32-36]. Furthermore, several integrated microfluidic devices (or LoC devices) [37-41] and $\mu$ PADs [42-45] have been presented for determining the creatinine concentration. For example, Dosso et al. [41] developed an integrated SIMPLE-based biosensor (named Creasensor) for the detection of creatinine in blood plasma samples. The platform combined fast bioassay on a self-powered SIMPLE microfluidic cartridge with an integrated signal processing unit and a simple but robust colorimetric read-out. The platform was validated on field in a single-blind study by measuring the creatinine levels in 16 creatinine-spiked plasma samples. An excellent agreement was observed between the measured concentration values and the spiked concentrations, over the creatinine range of $0.76 \sim 20 \mathrm{mg} / \mathrm{dL}$. Sununta et al. [45] presented a $\mu$ PAD for determining the creatinine concentration in urine samples by means of a Jaffé reaction process followed by colorimetric detection. The device was shown to achieve a wide linear range of $0.2-1 \mathrm{mM}$ with a limit of detection of $0.08 \mathrm{mM}$.

The present study proposes an integrated system for rapid human serum creatinine concentration measurement consisting of a paper-based chip and a detection system comprising a heating module, a voltage regulator module, a cooling module, a CMOS camera, a USB connector and a smartphone. In the proposed detection process, a Jaffé reaction is induced between the creatinine and alkaline picrate reagent implanted in the detection zone of the chip by heating the chip at $37^{\circ} \mathrm{C}$ for $5 \mathrm{~min}$ in the detection box. The color intensity of the resulting yellow-orange reaction complex is captured by the CMOS camera and transferred to the smartphone using the USB connector. Finally, the concentration of the creatinine sample is evaluated by analyzing the RGB (red, green and blue) color intensity of the reaction image using self-written software installed on the smartphone in the form of an app. Overall, the proposed system provides celerity, convenience, low-cost, miniaturization and automation for human serum creatinine concentration measurement.

\section{Materials and Methods}

\subsection{Reagent Preparation}

Creatinine powder and reagent (R1: sodium hydroxide; R2: picric acid) were purchased from Roche calibrator (Roche Diagnostics, Taipei, Taiwan) and Roche/Hitachi Creatinine plus (Roche Diagnostics, Germany). Creatinine detection was performed using a reagent solution consisting of $0.1 \mathrm{M}$ sodium hydroxide ( $\mathrm{R} 1, \mathrm{pH}>13.5)$ and $50 \mathrm{mM}$ picric acid ( $\mathrm{R} 2, \mathrm{pH}=6.5)$. Phosphate buffered saline (PBS) solution was prepared comprising $0.2 \mathrm{M}$ sodium dihydrogen phosphate $\left(\mathrm{NaH}_{2} \mathrm{PO}_{4}\right)$, de-ionized (DI) water and $0.15 \mathrm{M}$ sodium chloride $(\mathrm{NaCl})$. Finally, a standard $1000 \mathrm{mg} / \mathrm{dL}$ creatinine $\left(\mathrm{C}_{4} \mathrm{H}_{7} \mathrm{~N}_{3} \mathrm{O}\right)$ stock solution was prepared by mixing $0.1 \mathrm{~g}$ creatinine powder with $10 \mathrm{ml} 0.1 \mathrm{M} \mathrm{HCl}$. Control samples with creatinine concentrations in the range of $0.2 \sim 8 \mathrm{mg} / \mathrm{dL}$ were then prepared by diluting the stock solution with appropriate quantities of PBS solution.

\subsection{Fabrication of Paper-Based Chip}

Figure 1a-d show the main steps, including (a) pattern design, (b) wax printing, (c) heating wax process and $(\mathrm{d})$ reagent and sample dropped, in the fabrication process used to prepare the paper-based chip. The chip was fabricated on Advantech qualitative filter paper (No. 1, Toyo Roshi Kaisha Ltd., 
Tokyo, Japan; pore size: $6 \mu \mathrm{m}$; thickness: $0.2 \mathrm{~mm}$ ) and consisted of a circular reaction zone with a diameter of $3 \mathrm{~mm}$ bounded by an impermeable wax ring with an outer diameter of $5 \mathrm{~mm}$. The chip was designed using CorelDrawR Graphics Suite X5 software and printed using a commercial wax printer (Fuji Xerox ColorQube 8750, Japan). After printing, the chip was heated for 3 min at $120^{\circ} \mathrm{C}$ in a benchtop furnace (Vulcan A-550, Taiwan) to melt the wax and form a hydrophobic barrier through the thickness of the paper. Finally, the paper-based chip was bonded with a cardboard substrate using 3 M double-side tape (V1205, 3 M Comp., Taipei, Taiwan).

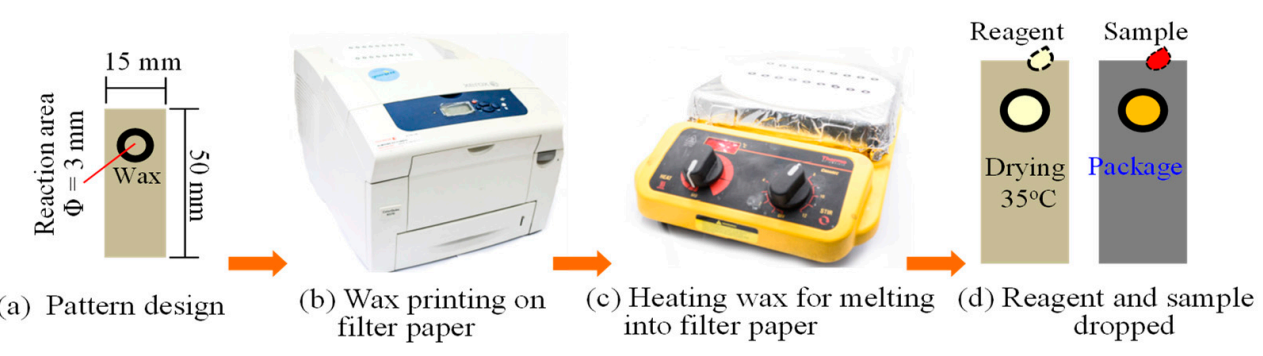

Figure 1. Schematic illustration showing main steps in fabrication procedure for paper-based chip.

\subsection{Detection System and Jaffé Chemical Reaction Process}

As shown in Figure 2, the main components of the detection system include a power source, a temperature controller, a voltage controller, a cooling module, a detection box and a smartphone (Xperia Z5, Sony Co., Tokyo, Japan) The detection box further contains a CMOS camera $(1920 \times 1080$ pixels, Dmatek Co. Ltd., Taichung, Taiwan), two LED light sources, a microheater, a chip holder and a connector. A more detailed and the function of the module in the detection system can be referred to our previous study [46].

In performing the creatinine detection process, $3 \mu \mathrm{L}$ of sample solution was dropped onto the reaction zone of the chip (reagent implanted with R1:R2 $=1 \mu \mathrm{L}: 2 \mu \mathrm{L}$ and dried at a temperature of $35^{\circ} \mathrm{C}$ for $\left.10 \mathrm{~min}\right)$. The chip was then inserted into the chip holder of the detection box and heated at $37^{\circ} \mathrm{C}$ for $5 \mathrm{~min}$ to induce a Jaffé reaction (i.e., Creatinine + Picric acid $\stackrel{\text { alkaline }}{\rightarrow}$ yellow-orange complex (see Scheme 1)). Images of the creatinine-picric complex were acquired by a built-in CMOS camera and transferred to a smartphone by means of the USB connector. Note that the smartphone was only applied to calculate the RGB values without catching images. Finally, the human serum creatinine concentration was derived using a self-written RGB color analysis app installed on the phone.
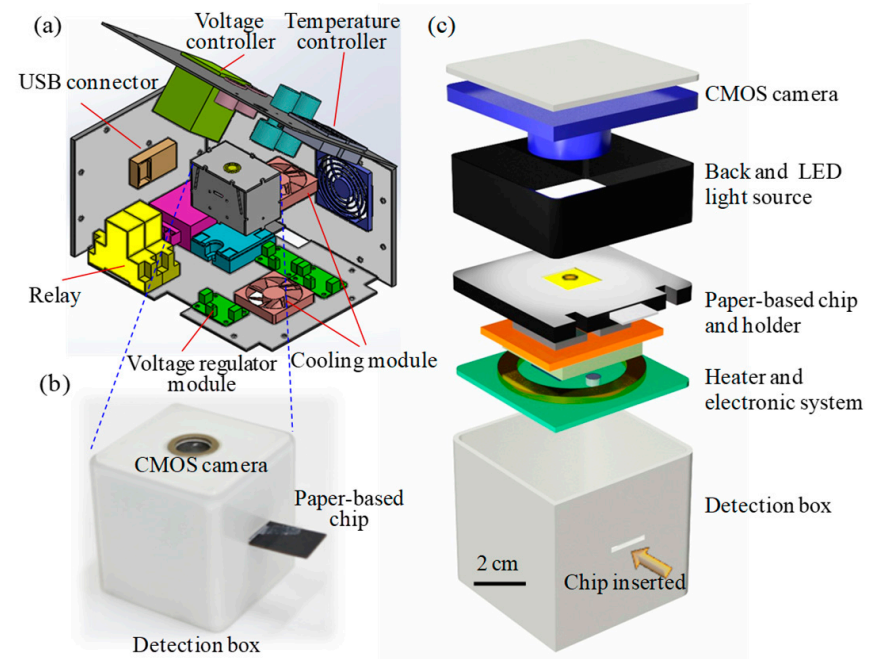

Figure 2. Photograph and schematic illustrations of: (a) main components of the smart detection device; $(\mathbf{b}, \mathbf{c})$ show detailed components of the detection box. 


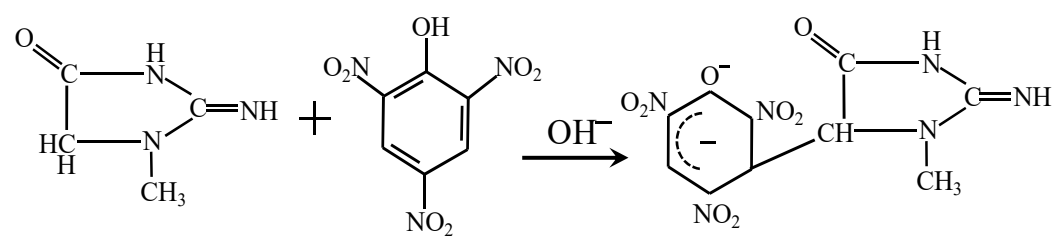

Creatinine

Picric acid

Creatinine-picric acid complex

Scheme 1. Jaffé reaction between creatinine sample and picric acid/ $\mathrm{NaOH}$ indicator.

\section{Results and Discussion}

\subsection{Effects of Reaction Time and Reagent Concentration}

A series of preliminary experiments were performed to investigate the effects of the Jaffé reaction time on the G (green) + B (blue) intensity of the reacted yellow-orange complex. Figure 3a presents the corresponding results obtained for creatinine control samples with concentrations of $0.2,4.0$ and $8.0 \mathrm{mg} / \mathrm{dL}$ given reaction times of $1 \sim 8 \mathrm{~min}$ and a constant reaction temperature of $37^{\circ} \mathrm{C}$. For reaction times of 1 3 min, the $\mathrm{G}$ (green) + B (blue) intensity steadily increases with an increasing reaction time. In other words, the reaction process between the reagent and the creatinine sample is incomplete. However, for reaction times of more than $5 \mathrm{~min}$, the $\mathrm{G}$ (green) + B (blue) intensity remains stable for all three samples. In other words, the reaction process is complete. Thus, in performing all the remaining experiments, the reaction time was set as $5 \mathrm{~min}$.
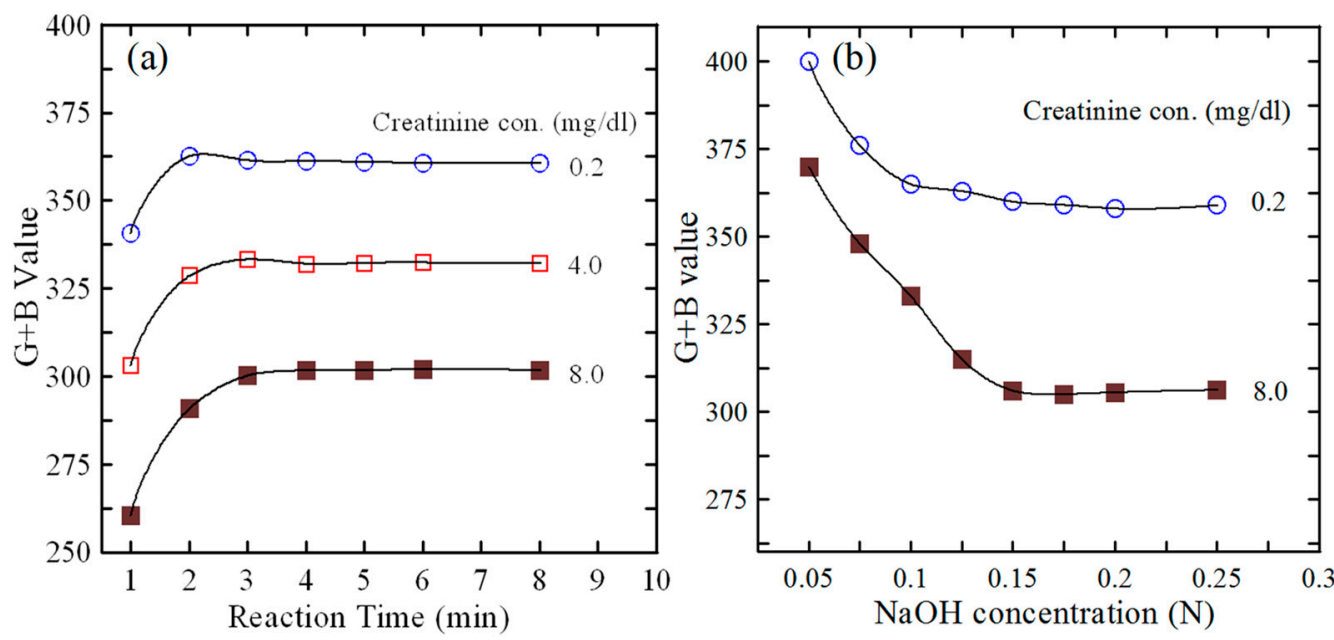

Figure 3. (a) Reaction time stability of samples with various creatinine concentrations given reaction temperature of $37^{\circ} \mathrm{C}$; (b) $\mathrm{G}+\mathrm{B}$ values of creatinine samples with concentrations of $0.2 \mathrm{mg} / \mathrm{dL}$ and $8 \mathrm{mg} / \mathrm{dL}$ given different $\mathrm{NaOH}$ concentrations and constant reaction time of $5 \mathrm{~min}$.

For RGB color analysis, a wide color distribution range is essential in improving the resolution and accuracy of the detection results. Figure $3 b$ shows the $G$ (green) + B (blue) intensity values of the reaction complexes obtained for 0.20 and $8 \mathrm{mg} / \mathrm{dL}$ creatinine control samples given $\mathrm{NaOH}$ reagent concentrations of $0.05 \sim 0.25 \mathrm{M}$, a reaction time of $5 \mathrm{~min}$ and a reaction temperature of $37^{\circ} \mathrm{C}$. For $\mathrm{NaOH}$ concentrations of less than $0.1 \mathrm{M}$, the $\mathrm{G}+\mathrm{B}$ values of the two samples differ by only $\sim 30(\mathrm{G}+\mathrm{B})$. However, as the $\mathrm{NaOH}$ concentration increases, the difference in the $\mathrm{R}+\mathrm{B}$ values of the samples also increases. For example, given an $\mathrm{NaOH}$ concentration of $0.15 \mathrm{M}$, the interval between the $\mathrm{G}+\mathrm{B}$ values of the two samples is equal to approximately $55(\mathrm{G}+\mathrm{B})$. In other words, the interval between the two values is more than 1.8 times higher than that obtained using $0.1 \mathrm{M} \mathrm{NaOH}$. Consequently, the $\mathrm{NaOH}$ concentration was set as $0.15 \mathrm{M}$ in all of the remaining detection tests. 


\subsection{Linearity of RGB Intensity Values and Calibration of Detection System}

To determine the optimal RGB signal for detection purposes, the intensities of the R (red), G (green) and B (blue) signals were observed for a reaction temperature of $37^{\circ} \mathrm{C}$, a reaction time of $5 \mathrm{~min}$ and creatinine samples with concentrations in the range of $0.2 \sim 8 \mathrm{mg} / \mathrm{dL}$. Figure 4 a shows the corresponding results. It is seen that the $R$ (red) intensity signal has a correlation coefficient of just $R^{2}=0.8603$ and is thus unsuitable for detection purposes. By contrast, the G (green) and B (blue) intensity signals both have correlation coefficients of more than 0.99 . In other words, both signals are highly correlated with the creatinine concentration and thus provide a reliable basis for creatinine detection.

To calibrate the proposed system, the G (green) + B (blue) intensity values were measured for five standard creatinine samples with concentrations ranging from $0.2 \sim 8 \mathrm{mg} / \mathrm{dL}$. For each sample, five separate measurements of the $G$ (green) + B (blue) intensity were obtained. The measurements were then averaged in order to obtain a representative value for the sample. In accordance with the results described above, the reaction process was performed using an $\mathrm{NaOH}$ concentration of $0.15 \mathrm{M}$, a reaction temperature of $37^{\circ} \mathrm{C}$ and a reaction time of $5 \mathrm{~min}$. Figure $4 \mathrm{~b}$ shows the intensity values obtained for the various control samples. Applying a regression analysis technique to the experimental results, the $\mathrm{G}$ (green) + B (blue) intensity value $(\mathrm{Y})$ is found to be related to the creatinine concentration $(X)$ as $Y=-9.4150 X+344.837$. Moreover, the correlation coefficient is equal to $R^{2}=0.9934$. In other words, the G (green) + B (blue) intensity varies linearly with the creatinine concentration over the normal creatinine range in human blood. Thus, the validity of the proposed system is confirmed.
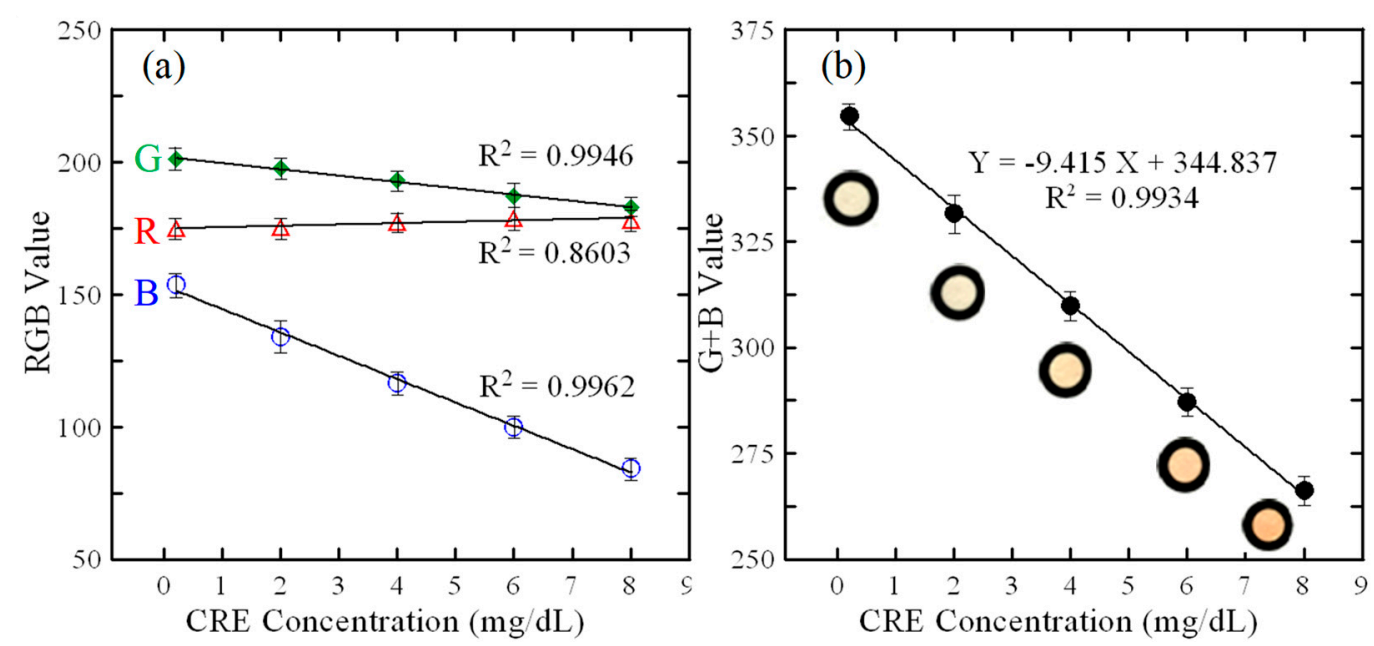

Figure 4. (a) RGB intensity values of creatinine samples and (b) variation of G (green) + B (blue) intensity (and associated color images) with creatinine concentration in the range of $0.2 \sim 8 \mathrm{mg} / \mathrm{dL}$. (Note that the reaction temperature and reaction time are $37^{\circ} \mathrm{C}$ and $5 \mathrm{~min}$, respectively.).

\subsection{Creatinine Detection in Real Samples}

The applicability of the proposed platform for clinical diagnostic purposes was investigated using human serum creatinine samples obtained from 32 adult volunteers (patients at National Cheng Kung University Hospital in Taiwan). These human serum creatinine samples are obtained from whole blood samples via a separation and purification process at the hospital. The detection results were compared with those obtained using a macroscale human serum creatinine assay technique (a spectrophotometry method performed using an automatic biochemistry analyzer/integrated system 7600, Hitachi High-Technologies Co., Tokyo, Japan) at a major university hospital in Taiwan (National Cheng Kung University Hospital, Tainan, Taiwan). Figure 5a presents a scatter-plot of the results obtained for the 32 samples by the two methods. As shown in Figure 5b, the two sets of results are related as $\mathrm{Y}=0.9907 \mathrm{X}+0.0001$, with a correlation coefficient of 0.9994 . In other words, the ability of 
the proposed paper-based human serum creatinine system to detect the creatinine concentration in real-world samples is confirmed.
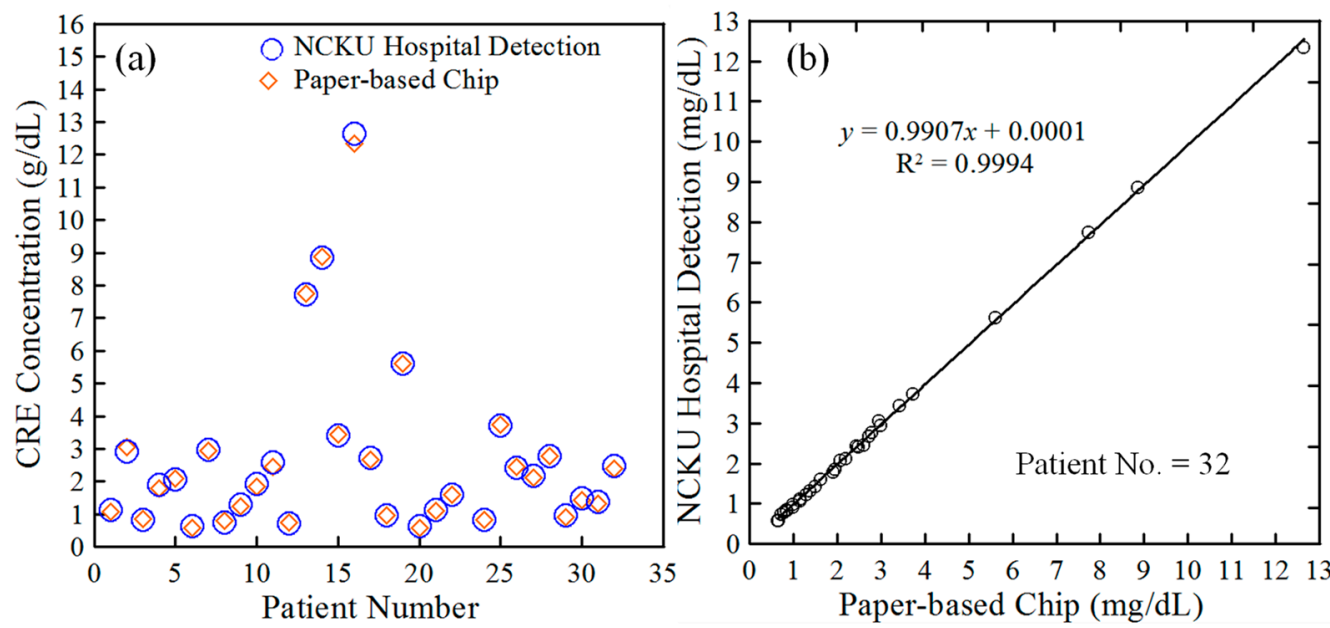

Figure 5. Comparison of human serum creatinine detection results obtained using proposed paper-based system and traditional macroscale system (a) a scatter-plot and (b) a related-plot by the two methods.

\section{Conclusions}

This study has presented a simple method based on Jaffé reaction theory for performing creatinine concentration detection using a paper-based chip and a smart detection system comprising a detection box, a temperature controller, a voltage regulator, a power source, a USB connector and a smartphone. The detection box further comprises a CMOS camera, two LED light sources, a chip holder and a hotplate. In the proposed system, the reaction region of the paper chip is implanted with $50 \mathrm{mM}$ picric acid reagent and $0.15 \mathrm{M} \mathrm{NaOH}$ and the chip is then dried at $35^{\circ} \mathrm{C}$ for $20 \mathrm{~min}$. In the detection process, the serum creatinine sample is dripped onto the reaction zone of the chip and the chip is then transferred to the hotplate in the detection system, where a Jaffé reaction is induced by heating at $37^{\circ} \mathrm{C}$ for $5 \mathrm{~min}$. The experimental results have shown that the creatinine concentration measurements obtained by the proposed platform for 32 adult volunteers are in excellent agreement with those obtained using a conventional macroscale technique $\left(\mathrm{R}^{2}=0.9994\right)$. In other words, the feasibility of the proposed paper-based system for practical clinical purposes is confirmed. Overall, the proposed method provides a simple, portable and low-cost approach for human serum creatinine concentration detection. Thus, it represents an ideal solution for a wide range of diagnostic and POCT applications.

Author Contributions: L.-M.F., C.-C.T. and W.-J.J. conceived and designed the experiments; W.-J.J. performed the experiments; L.-M.F. and R.-J.Y. analyzed the data; W.-J.J. contributed reagents/materials/analysis tools; L.-M.F. wrote the paper.

Acknowledgments: The authors would like to thank the Ministry of Science and Technology of Taiwan for the financial support of this study under Grant Nos. MOST-104-2221-E-006-154-MY3, MOST 106-2314-B-020-002-MY3, MOST 106-2221-E-020-019-MY3, MOST 106-2622-B-020-001-CC2, MOST 107-2622-B-020-003-CC2 and 107TFDA-A-106.

Conflicts of Interest: The authors declare no conflict of interest.

\section{References}

1. Pundir, C.S.; Yadav, S.; Kumar, A. Creatinine sensors. Trends Anal. Chem. 2013, 50, 42-52. [CrossRef]

2. Songjaroen, T.; Maturos, T.; Sappat, A.; Tuantranont, A.; Laiwattanapaisal, W. Portable microfluidic system for determination of urinary creatinine. Anal. Chim. Acta 2009, 647, 78-83. [CrossRef] [PubMed] 
3. Randviir, E.P.; Banks, E. Analytical methods for quantifying creatinine within biological media. Sens. Actuators B Chem. 2013, 183, 239-252. [CrossRef]

4. Wang, A.B.; Fang, P.H.; Su, Y.C.; Hsieh, Y.W.; Lin, C.W.; Chen, Y.T.; Hsu, Y.C. A novel lab-on-a-chip design by sequential capillary-gravitational valves for urinary creatinine detection. Sens. Actuators B Chem. 2016, 222, 721-727. [CrossRef]

5. Chen, S.; Song, Y.; Shi, F.; Liu, Y.; Ma, Q. Sensitive detection of picric acid based on creatinine-capped solid film assembled by nitrogen-doped graphene quantum dots and chitosan. Sens. Actuators B Chem. 2016, 231, 634-640. [CrossRef]

6. Blel, A.; Orven, Y.; Pallet, N.; Chasse, J.F.; Vedie, B.; Loriot, M.A.; Paul, J.L.; Narjoz, C. Pegylated liposomal doxorubicin $\left(\right.$ Caelyx $\left.{ }^{\circledR}\right)$ interference with the spectrophotometric Jaffemethod for quantitative determination of creatinine in human plasma. Clin. Biochem. 2017, 50, 455-457. [CrossRef] [PubMed]

7. Duong, H.D.; Rhee, J.I. Development of ratiometric fluorescent biosensors for the determination of creatine and creatinine in urine. Sensors 2017, 17, 2570. [CrossRef] [PubMed]

8. Vitali, L.; Gonçalves, S.; Rodrigues, V.; Fávere, V.T.; Micke, G.A. Development of a fast method for simultaneous determination of hippuric acid, mandelic acid and creatinine in urine by capillary zone electrophoresis using polymer multilayer-coated capillary. Anal. Bioanal. Chem. 2017, 409, 1943-1950. [CrossRef] [PubMed]

9. Hanif, S.; John, P.; Gao, W.; Saqib, M.; Qi, L.; Xu, G. Chemiluminescence of creatinine $/ \mathrm{H}_{2} \mathrm{O}_{2} / \mathrm{Co}^{2+}$ and its application for selective creatinine detection. Biosens. Bioelectron. 2016, 75, 347-351. [CrossRef] [PubMed]

10. Langsi, V.K.; Ashu-Arrah, B.A.; Ward, N.; Glennon, J.D. Synthesis and characterisation of non-bonded $1.7 \mu \mathrm{m}$ thin-shell (TS1.7-100 nm) silica particles for the rapid separation and analysis of uric acid and creatinine in human urine by hydrophilic interaction chromatography. J. Chromatogr. A 2017, 1506, 37-44. [CrossRef] [PubMed]

11. Diouf, A.; Motia, S.; El Alami, N.; El Bari, N.; Bouchikhi, B. Development and characterization of an electrochemical biosensor for creatinine detection in human urine based on functional molecularly imprinted polymer. J. Electroanal. Chem. 2017, 788, 44-53. [CrossRef]

12. Saidi, T.; Moufid, M.; Zaim, O.; Bari, N.E.; Bouchikhi, B. Voltammetric electronic tongue combined with chemometric techniques for direct identification of creatinine level in human urine. Measurement 2018, 115, 178-184. [CrossRef]

13. Krishnegowda, A.; Padmarajaiah, N.; Anantharaman, S.; Honnur, K. Spectrophotometric assay of creatinine in human serum sample. Arab. J. Chem. 2017, 10, S2018-S2024. [CrossRef]

14. Suzuki, M.; Furuhashi, M.; Sesoko, S.; Kosuge, K.; Maeda, T.; Todoroki, K.; Inoue, K.; Min, J.Z.; Toyo'oka, T. Determination of creatinine-related molecules in saliva by reversed-phase liquid chromatography with tandem mass spectrometry and the evaluation of hemodialysis in chronic kidney disease patients. Anal. Chim. Acta 2016, 911, 92-99. [CrossRef] [PubMed]

15. Guinovart, T.; Hernández-Alonso, D.; Adriaenssens, L.; Blondeau, P.; Martínez-Belmonte, M.; Rius, F.X.; Andrade, F.J.; Ballester, P. Recognition and sensing of creatinine. Angew. Chem. Int. Ed. 2016, 55, 1-7. [CrossRef] [PubMed]

16. Guinovart, T.; Hernández-Alonso, D.; Adriaenssens, L.; Blondeau, P.; Rius, F.X.; Ballester, P.; Andrade, F.J. Characterization of a new ionophore-based ion-selective electrode for the potentiometric determination of creatinine in urine. Biosens. Bioelectron. 2017, 87, 587-592. [CrossRef] [PubMed]

17. Raveendran, J.; Resmi, P.E.; Ramachandran, T.; Nair, B.G.; Babu, T.G.S. Fabrication of a disposable non-enzymatic electrochemical creatinine sensor. Sens. Actuators B Chem. 2017, 243, 589-595. [CrossRef]

18. Hooshmand, S.; Es'haghi, Z. Microfabricated disposable nanosensor based on CdSe quantum dot/ionic liquid-mediated hollow fiber-pencil graphite electrode for simultaneous electrochemical quantification of uric acid and creatinine in human samples. Anal. Chim. Acta 2017, 972, 28-37. [CrossRef] [PubMed]

19. Sutariya, P.G.; Pandya, A.; Lodha, A.; Menon, S.K. A simple and rapid creatinine sensing via DLS selectivity, using calix[4] arene thiol functionalized gold nanoparticles. Talanta 2016, 147, 590-597. [CrossRef] [PubMed]

20. Alula, M.T.; Karamchand, L.; Hendricks, N.R.; Blackburn, J.M. Citrate-capped silver nanoparticles as a probe for sensitive and selective colorimetric and spectrophotometric sensing of creatinine in human urine. Anal. Chim. Acta 2018, 1007, 40-49. [CrossRef] [PubMed] 
21. Pal, S.; Lohar, S.; Mukherjee, M.; Chattopadhyay, P.; Dhara, K. A fluorescent probe for the selective detection of creatinine in aqueous buffer applicable to human blood serum. Chem. Commun. 2016, 52, 13706-13709. [CrossRef] [PubMed]

22. Roy, S.; Roy, A.; Panja, R.; Samanta, S.; Chakrabarti, S.; Yu, P.L.; Maikap, S.; Cheng, H.M.; Tsai, L.N.; Qiu, J.T. Comparison of resistive switching characteristics by using e-gun/sputter deposited SiOx film in $\mathrm{W} / \mathrm{SiOx} / \mathrm{TiN}$ structure and $\mathrm{pH} /$ creatinine sensing through iridium electrode. J. Alloy Compd. 2017, 726, 30-40. [CrossRef]

23. Nieh, C.H.; Tsujimura, S.; Shirai, O.; Kano, K. Amperometric biosensor based on reductive $\mathrm{H}_{2} \mathrm{O}_{2}$ detection using pentacyanoferrate-bound polymer for creatinine determination. Anal. Chim. Acta 2013, 767, 128-133. [CrossRef] [PubMed]

24. Kumar, P.; Jaiwal, R.; Pundir, C.S. An improved amperometric creatinine biosensor based on nanoparticles of creatininase, creatinase and sarcosine oxidase. Anal. Biochem. 2017, 537, 41-49. [CrossRef] [PubMed]

25. Du, H.; Chen, R.Y.; Du, J.J.; Fan, J.L.; Peng, X.J. Gold nanoparticle-based colorimetric recognition of creatinine with good selectivity and sensitivity. Ind. Eng. Chem. Res. 2016, 55, 12334-12340. [CrossRef]

26. Parmar, A.K.; Valand, N.N.; Solanki, K.B.; Menon, S.K. Picric acid capped silver nanoparticles as a probe for colorimetric sensing of creatinine in human blood and cerebrospinal fluid samples. Analyst 2016, 141, 1488-1498. [CrossRef] [PubMed]

27. Kasap, B.O.; Marchenko, S.V.; Soldatkin, O.O.; Dzyadevych, S.V.; Kurc, B.A. Biosensors based on nano-gold/zeolite-modified Ion selective field-effect transistors for creatinine detection. Nanoscale Res. Lett. 2017, 12, 162-172. [CrossRef] [PubMed]

28. Lee, C.Y.; Fu, L.M. Recent advances and applications of micromixers. Sens. Actuators B Chem. 2018, 259, 677-702. [CrossRef]

29. Yeh, E.; Fu, C.; Hu, L.; Thakur, R.; Feng, J.; Lee, L.P. Self-powered integrated microfluidic point-of-care low-cost enabling (SIMPLE) chip. Sci. Adv. 2017, 3, e1501645. [CrossRef] [PubMed]

30. Swain, B.; Hong, M.H.; Kang, L.; Kim, B.S.; Kim, N.H.; Lee, C.G. Optimization of CdSe nanocrystals synthesis with a microfluidic reactor and development of combinatorial synthesis process for industrial production. Chem. Eng. J. 2017, 308, 311-321. [CrossRef]

31. Kong, X.; Chong, X.; Squire, K.; Wang, A.X. Microfluidic diatomite analytical devices for illicit drug sensing with ppb-Level sensitivity. Sens. Actuators B Chem. 2018, 259, 587-595. [CrossRef] [PubMed]

32. Kaur, G.; Tomar, M.; Gupta, V. Development of a microfluidic electrochemical biosensor: Prospect for point-of-care cholesterol monitoring. Sens. Actuators B Chem. 2018, 261, 460-466. [CrossRef]

33. Frank, P.; Haefner, S.; Elstner, M.; Richter, A. Fully-programmable, low-cost, "do-it-yourself" pressure source for general purpose use in the microfluidic laboratory. Inventions 2016, 1, 13. [CrossRef]

34. Ynag, R.J.; Fu, L.M.; Hou, H.H. Review and perspectives on microfluidic flow cytometers. Sens. Actuators $B$ Chem. 2018, 266, 26-45. [CrossRef]

35. Han, T.; Zhang, L.; Xu, H.; Xuan, J. Factory-on-chip: Modularised microfluidic reactors for continuous mass production of functional materials. Chem. Eng. J. 2017, 326, 765-773. [CrossRef]

36. Chung, J.; Hwang, H.Y.; Chen, Y.; Lee, T.Y. Microfluidic packaging of high-density CMOS electrode array for lab-on-a-chip applications. Sens. Actuators B Chem. 2018, 254, 542-550. [CrossRef]

37. Huang, C.J.; Lin, J.L.; Chen, P.H.; Syu, M.J.; Lee, G.B. A multi-functional electrochemical sensing system using microfluidic technology for the detection of urea and creatinine. Electrophoresis 2011, 32, 931-938. [CrossRef] [PubMed]

38. Wang, S.; Li, X.; Yang, J.; Yang, X.; Hou, F.; Chen, Z. Rapid determination of creatinine in human urine by microchip electrophoresis with LED induced fluorescence detection. Chromatographia 2012, 75, 1287-1293. [CrossRef]

39. Lin, C.C.; Hsu, J.L.; Tseng, C.C.; Lee, G.B. An integrated microfluidic system for the determination of microalbuminuria by measuring the albumin-to-creatinine ratio. Microfluid. Nanofluid. 2011, 10, 1055-1067. [CrossRef]

40. Lin, Y.H.; Wang, S.H.; Wu, M.H.; Pan, T.M.; Lai, C.S.; Luo, J.D.; Chiou, C.C. Integrating solid-state sensor and microfluidic devices for glucose, urea and creatinine detection based on enzyme-carrying alginate microbeads. Biosens. Bioelectron. 2013, 43, 328-335. [CrossRef] [PubMed] 
41. Dosso, F.D.; Decrop, D.; Pérez-Ruiz, E.; Daems, D.; Agten, H.; Al-Ghezi, O.; Bollen, O.; Breukers, J.; Rop, F.D.; Katsafadou, M.; et al. Creasensor: SIMPLE technology for creatinine detection in plasma. Anal. Chim. Acta 2018, 1000, 191-198. [CrossRef] [PubMed]

42. Talalak, K.; Noiphung, J.; Songjaroen, T.; Chailapakul, O.; Laiwattanapaisal, W. A facile low-cost enzymatic paper-based assay for the determination of urine creatinine. Talanta 2015, 144, 915-921. [CrossRef] [PubMed]

43. Sittiwong, J.; Unob, F. Paper-based platform for urinary creatinine detection. Anal. Sci. 2016, 32, 639-643. [CrossRef] [PubMed]

44. Tambaru, D.; Rupilu, R.H.; Nitti, F.; Gauru, I.; Suwari. Development of paper-based sensor coupled with smartphone detector for simple creatinine determination. AIP Conf. Proc. 2017, 1823, 020095.

45. Sununta, S.; Rattanarat, P.; Challapakul, O.; Praphairaksit, N. Microfluidic paper-based analytical devices for determination of creatinine in urine samples. Anal. Sci. 2018, 34, 109-113. [CrossRef] [PubMed]

46. Liu, C.C.; Wang, Y.N.; Fu, L.M.; Chen, K.L. Microfluidic paper-based chip platform for benzoic acid detection in food. Food Chem. 2018, 249, 162-167. [CrossRef] [PubMed]

(C) 2018 by the authors. Licensee MDPI, Basel, Switzerland. This article is an open access article distributed under the terms and conditions of the Creative Commons Attribution (CC BY) license (http:/ / creativecommons.org/licenses/by/4.0/). 